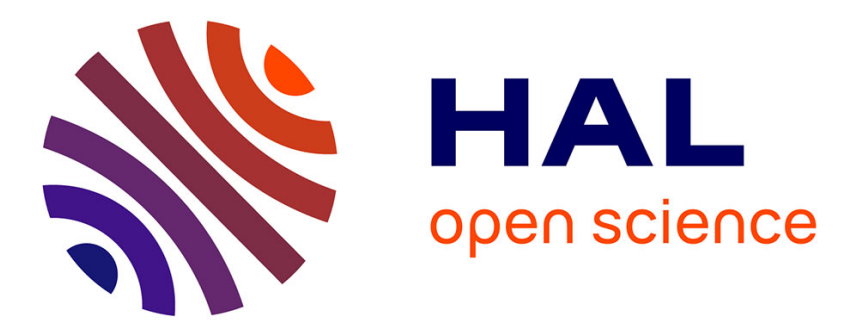

\title{
Contaminant free end-capped acetylene PMC for sub-Doppler spectroscopy
}

Thomas Billotte, Matthieu Chafer, Martin Maurel, Foued Amrani, Frédéric Gérôme, Benoît Debord, Fetah Benabid

\section{- To cite this version:}

Thomas Billotte, Matthieu Chafer, Martin Maurel, Foued Amrani, Frédéric Gérôme, et al.. Contaminant free end-capped acetylene PMC for sub-Doppler spectroscopy. Conference on Laser and Electro-Optics /Europe (CLEO/Europe-EQEC 2019), Jun 2019, OSA, Jun 2019, Munich, Germany. Paper CH-P.17. hal-02330820

\section{HAL Id: hal-02330820 \\ https://hal.science/hal-02330820}

Submitted on 23 Nov 2020

HAL is a multi-disciplinary open access archive for the deposit and dissemination of scientific research documents, whether they are published or not. The documents may come from teaching and research institutions in France or abroad, or from public or private research centers.
L'archive ouverte pluridisciplinaire HAL, est destinée au dépôt et à la diffusion de documents scientifiques de niveau recherche, publiés ou non, émanant des établissements d'enseignement et de recherche français ou étrangers, des laboratoires publics ou privés. 


\title{
Contaminant free end-capped acetylene PMC for sub-Doppler spectroscopy
}

\author{
Thomas Billotte $^{1}$, Matthieu Chafer ${ }^{1,2}$, Martin Maurel ${ }^{1,2}$, Foued Amrani $^{1}$, Frédéric Gérôme ${ }^{1,2}$, Benoit \\ Debord $^{1,2}$, Fetah Benabid ${ }^{1,2}$ \\ 1. GPPMM Group, Xlim Research Institute, CNRS UMR 7252, University of Limoges, 87000 Limoges, France \\ 2. GLOphotonics SAS, 123 avenue Albert Thomas 87060 Limoges Cedex
}

Gas-filled Hollow Core Photonic Cristal Fibres (HCPCF) or Photonic MicroCell (PMC) [1] has proven to offer an outstanding gas-cell for laser metrology and spectroscopy applications. Sub-Doppler spectral features, generated via electromagnetically induced transparency (EIT) or saturated absorption (SA), have been generated in molecular gases despite the weak strength of their optical transitions [1-4], and an optical frequency reference with excellent accuracy has been demonstrated [1]. So far, the reported stand-alone PMCs are either made by hermetically splicing the HCPCF tips to an all-solid optical fibre [1,2] or by encapsulating them to a glass cell [3]. All these techniques show limitations. For example, the splicing based all-fibre PMC technique is not adapted to all fibres as it requires matching the outer-diameter and/or mode-field-diameters of the two fibres. Also the use of fibre tapering to reduce this mismatch [2] remains too cumbersome for the obtained splice-loss figures, which are $>2 \mathrm{~dB}$ and exhibit asymmetric loss. Furthermore, the use of Helium (He) gas during the "air-ambient" splicing process to avoid air pollution in the fibre core renders this technique too sensitive to residual gas contamination. Conversely, the technique of encapsulating the fibre tip in an enlarged borosilicate capillary [3] presents potential contamination during and after fabrication because of the use of Epoxy glue, and the ensued outgassing, which is detrimental for optimized observation of sub-Doppler features and for the life time of the PMC.

Here, we report on fabrication and spectroscopic (EIT and SA spectroscopy) characterisation of contaminant free acetylene PMC where no He or glue is required. The assembly process of this PMC is based on end-capping both ends of a HCPCF by collapsing a sleeve capillary while the system is still connected to the vacuum preventing any air pollution. The end-cap is then polished and mounted onto FC/APC connectors for easy system integration. Fig. 1(a) shows a photography of the developed PMC with a fibre patchcord-like physical-outline. The PMC is made with a $7 \mathrm{~m}$ long section of an IC-HCPCF with low loss of $10 \mathrm{~dB} / \mathrm{km}$ around $1540 \mathrm{~nm}$. The IC-HCPCF has a hypocycloid core of an inner diameter of $30 \mu \mathrm{m}$. The fibre was filled with acetylene at a pressure of $0.04 \mathrm{mbar}$ corresponding to a pressure collisional broadening of $8 \mathrm{MHz}$ [4]. The loss of each end cap is found around $1 \mathrm{~dB}$. The mode quality is stable motionally, illustrated by the near field intensity profile in Fig.1(b). The formed $\mathrm{C}_{2} \mathrm{H}_{2}$ PMC was characterised by generating and monitoring sub-Doppler transparencies using both EIT and SA spectroscopy. Fig. 1(c) shows the PMC transmission EIT trace when pumped at P13 of the acetylene $v_{1}+v_{3}$ rovibrational overtone band and probed at the R13. The EIT contrast and FWHM evolution with the pump power is shown in Fig.1(d), expressed in Rabi frequency. Both quantities fit well with the expression in [4]. The EIT linewidth shows an asymptotic minimum of $18 \pm 3 \mathrm{MHz}$. This figure is close to the transit time induced linewidth which is about $19 \mathrm{MHz}$ for the fundamental core mode. Consequently, no collision dephasing is observed. Furthermore, we generated SA (Fig.1(e,f)) with a contrast of $8 \%$ and a linewidth of $17 \mathrm{MHz}$.

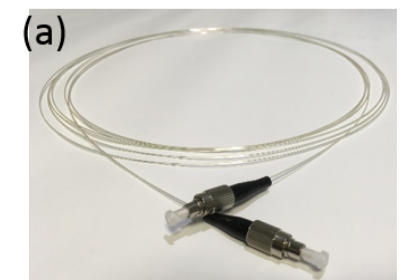

(b)

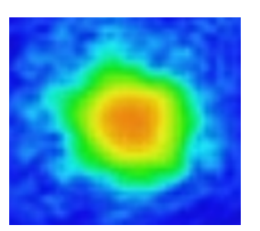

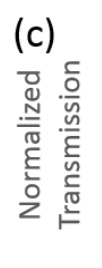

(d)

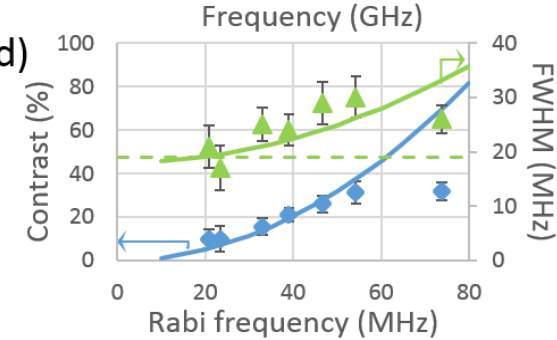

(e)

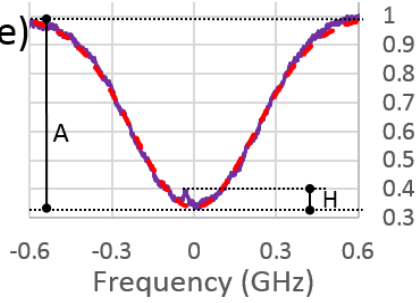

(f)

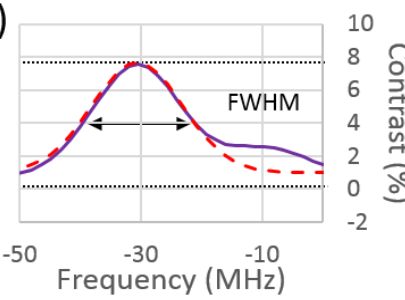

Fig. 1 (a) Overall picture of the FC/APC connectorized PMC, (b) PMC output near field mode at 1530nm, (c) EIT spectrum of R13 line pumped by at 100mW centered on the P13 (line) and a Gaussian fit (dashed line). (d) The EIT contrast (blue) and FWHM (green) vs Rabi frequency for experimental data (dots) and theory (line). (e) SA measurement of the P9 line with $32 \mathrm{~mW}$ pump power (Gaussian fit in dashed line). (f) Difference between SA spectrum and Gaussian fit from (e).

This research is funded through la région Nouvelle-Aquitaine.

[1] F. Benabid et al., Nature 434, 488 (2005).

[2] N.Wheeler et al., Opt. Lett. 35, 1875 (2010).

[3] M.Triches et al., App.Phys. 121, 251 (2015).

[4] F. Benabid et al., Opt. Expr. 13, 5694 (2005). 